\title{
Volatile metabolites of willows determining host discrimination by adult Plagiodera versicolora
}

\author{
Jiahao Ling ${ }^{1}$ Xiaoping $\mathrm{Li}^{1} \cdot$ Guo Yang $^{1}$. \\ Tongming Yin ${ }^{1}$
}

Received: 23 May 2020 / Accepted: 5 July 2020 / Published online: 15 June 2021

(C) The Author(s) 2021

\begin{abstract}
Plagiodera versicolora Laicharting is a highly damaging leaf beetle foraging on willow leaves. In willow germplasm collections, observation has shown that Salix suchowensis Cheng was severely foraged by this leaf beetle while Salix triandra L. was damage free or only slightly damaged. Results of olfactometer bioassays show that the headspace volatiles from leaves of $S$. triandra significantly repelled adult beetles, suggesting that this species produces volatile repellents against $P$. versicolora. $S$. suchowensis had no effect on the beetles. Gas chromatography-mass spectrometry was carried out to profile the headspace volatile organic compounds and 23 compounds from leaves of the alternate species in significantly different concentrations were detected. The effects of 20 chemical analogs on host discrimination were examined. Olfactory response to these chemicals showed that $o$-cymene, a $S$. suchowensis specific constituent, significantly attracted adult $P$. versicolora. In contrast, cis-3-hexenyl acetate, a constituent concentrated more in $S$. triandra than in $S$. suchowensis, significantly repelled beetles. Mixing $o$-cymene and cis-3-hexenyl
\end{abstract}

Project funding: The work was supported by the National Natural Science Foundation of China (grants 31570662 and 31500533). It was also enabled by the priority academic program development at Nanjing Forestry University.

The online version is available at http://www.springerlink.com.

Corresponding editor: Yanbo Hu.

Tongming Yin

tmyin@njfu.com.cn

1 The Key Laboratory for Tree Genetics and Biotechnology of Jiangsu Province and Educational Department of China, College of Forestry, Nanjing Forestry University, Nanjing 200137, People's Republic of China acetate in comparable concentrations as in the volatiles of S. suchowensis demonstrated that the latter could mask the attracting effect of the former, causing a neutral response by adult beetles to leaves of $S$. suchowensis against clean air. In addition, chemical analogs have the same effect as plants when resembling volatile organic compounds in real samples. Two volatile metabolites were detected triggering host discrimination by one of the most damaging insect pests to host and non-host willows. The two metabolites are of considerable potential for use as olfactory signs in managing the beetles.

Keywords Herbivore insect - Olfactory response . Volatile organic compounds - Cis-3-hexenyl acetate . $O$-cymene

\section{Introduction}

Plagiodera versicolora Laicharting (willow beetle) feeds exclusively on leaves of species of Salicaceae and is the most damaging herbivore insect on Salix suchowensis Cheng as well as on many other willow species (Ishihara and Ohgushi 2008). Willow beetles forage on young leaves and cause bud death (Wade and Breden 1986). Several studies have shown that food preference of the beetles was significantly impacted by many host factors. For instance, secondary metabolites of Salix integra Thunb., chlorogenic acid and 3,5-dicaffeoyl quinic acid, were identified as antifeedants that would inhibit attack by insects and grazing animals, whereas 1,2-dilinolenoyl-3-galactopyranosyl glycerol could stimulate trophic behavior, the position occupied in the food chain, of the beetles (Jassbi 2003). Raupp (1985) reported that leaf toughness affected the morphology, feeding behavior, and ultimately shaped the spatiotemporal distribution of $P$. versicolora. 
Adult willow beetles preferentially feed on young leaves of Salicaceae species (Raupp and Denno 1983), leading to an increase in mortality of willows due to necrosis of apical buds. Leaf age has also been reported to affect the choice of oviposition for female adults (King et al. 1998).

How do insects discriminate their preferred food resource? Conchou et al. (2019) proposed that herbivore selection of plants relies heavily on olfactory clues, although they also have visionary, mechanoreception and gustation mechanisms (Miller and Strickler 1984). Multiple lines of evidence support this hypothesis. For example, host selection by the spittle bug (Mahanarva spectabilis Distant) was affected by several volatile organic compounds (VOCs) emitted from forage grasses (Silva et al. 2019). Whereas the strawberry leaf beetle (Galerucella vittaticollis Baly) used a component in the headspace volatiles of several host plants as olfactory clues (Hori et al. 2006). For the pollen beetle Meligethes aeneus Fab., they were more attracted by volatiles from their most preferred host, rapeseed, Brassica napus L. (Ruther and Thiemann 1997). Plant VOCs are important to insects for finding hosts and for discerning non-hosts. Non-host plants succeed in affecting herbivore behavior in two possible ways. First, the VOCs mask those of host plants so that efficiency of host finding is greatly reduced, which was the case for the carrot fly (Uvah and Coaker 1984), several beetle species (McNair et al. 2000; Zhang and Schlyter 2004; Hori et al. 2006; Kerr et al. 2017) and some moth species (Asare-Bediako et al. 2010; Jactel et al. 2011). Secondly, VOCs released from non-host plants contain deterrent chemicals, thus insects are repelled (Nottingham and Hardie 1993) or normal development is disturbed after landing on the plants (Nishida et al. 1990; McNair et al. 2000; Wang et al. 2016).

For $P$. versicolora, it was shown that it could determine host status by odor (Yoneya et al. 2009). Through years of empirical observation, we found that infestation by willow beetles was severe on germplasm collections of Salix suchowensis, while the collections of Salix triandra L. were pest free. In this study, olfactory response tests were carried out with adult $P$. versicolora with leaves of $S$. suchowensis and $S$. triandra. Subsequently, VOCs emitted from the leaves of the alternate species were analyzed by gas chromatography mass spectrometry (GC-MS), and effects on hosts for the VOCs with different concentrations in the two species were examined with chemical analogs. We aimed to identify the VOCs underlying host discrimination for adult $P$. versicolora in host and non-host willows.

\section{Materials and methods}

A large germplasm collection of S. suchowensis and S. triandra maintained at the Baima Forest Farm in Nanjing, Jiangsu
Province. Cuttings propagated with clone "DB134" of $S$. triandra and "XY12" of $S$. suchowensis were produced in the greenhouse of the Nanjing Forestry University in February 2018. Leaves were collected from the top first node to the top fifth node on the shoots in June 2018. Adult P. versicolora were collected from the willow plantation at Baima Forest Farm $\left(118^{\circ} 48^{\prime} \mathrm{E}, 32^{\circ} 04^{\prime} \mathrm{N}\right)$ and reared in an incubator at $27{ }^{\circ} \mathrm{C}, 65 \% \pm 10 \%$ relative humidity, and under $16 \mathrm{~h}$ light, $8 \mathrm{~h}$ dark photoperiod. All adults were from the following generations of the initial collection. The duration of development from egg to adult emergence is approximately three weeks. Emerging beetles were provided with poplar leaves for 4-6 days of adult sexual maturation. Before the tests, the adults were starved for $12 \mathrm{~h}$, and both male and females were tested.

\section{Analyzing the headspace volatile organic compounds}

Headspace VOCs emitted from leaves of S. suchowensis and $S$. triandra were extracted using solid-phase micro extraction (SPME) in the headspace mode. Separation and identification of the constituents were carried out by GC-MS. For volatile extraction, 2-g fresh leaves were cut into pieces, and placed into a $50 \mathrm{~mL}$ vial. The headspace of the vial was extracted with SPME (65 $\mu \mathrm{m}$ PDMS/DVB, Supelco Inc., Bellefonte, PA., USA) for one hour at $50{ }^{\circ} \mathrm{C}$, which was based on a series of preliminary experiments.

The GC-MS (Trace ISQ-LT; Thermo Fisher Scientific Co., Waltham, MA, USA) was equipped with a DB-5 column $(30 \mathrm{~m} \times 0.25 \mathrm{~mm} \times 0.25 \mu \mathrm{m}$, Agilent $\mathrm{J} \& \mathrm{~W})$ and helium was used as the carrier gas at a column head speed of $1 \mathrm{~mL} / \mathrm{min}$. GC was set for splitless injection. The temperature program of the column oven was $40^{\circ} \mathrm{C}$ (2-min hold), $6{ }^{\circ} \mathrm{C} \mathrm{min}{ }^{-1}$ to $250{ }^{\circ} \mathrm{C}$ (5-min hold). The MS parameters were set at ionization energy of $70 \mathrm{eV}$ and a scan range of 45-450 U. Six replicates were used to conduct qualitative and quantitative analyses of leaf volatiles of the two willow species.

\section{Olfactometer bioassays}

The olfactory responses of adult willow beetles to leaf VOCs were investigated with a glass Y-tube olfactometer $(8 \mathrm{~cm}$ long $\times 0.5 \mathrm{~cm}$ radius, $75^{\circ} \mathrm{Y}$ angle). The stem of the Y-tube was connected to a rubber hose where the test beetles were released. Each arm was connected to a $50 \mathrm{~mL}$ air chamber, an airflow $(500 \mathrm{~mL} / \mathrm{min})$ was introduced into each chamber through activated charcoal and purified-water using an air pump. All tests were performed under ambient temperatures at $25 \pm 1{ }^{\circ} \mathrm{C}$ and relative humidity of $80 \% \pm 10 \%$ (Koschier et al. 2017).

Beetles were placed into the stem of the olfactometer, with each arm defined a "finishing line" at $3 \mathrm{~cm}$ from the 
end of the long stem. The selection behavior was recorded by observing if a beetle crossed the finishing line of the corresponding Y-tube glass connecting to the sample vial within 5 min. If a beetle did not cross the finishing line within $5 \mathrm{~min}$, it was recorded as 'pest did not make a selection'. The blend and control arms were exchanged after every 20 individual insects, and the glass Y-tube was washed in $75 \%$ ethanol and oven-dried at $90{ }^{\circ} \mathrm{C}$ after testing every 40 insects. The host-selection behavior was estimated by the excess proportion index (EPI) (Hori et al. 2006):

$\mathrm{EPI}=\frac{\mathrm{Nt}-\mathrm{Nc}}{\mathrm{Nt}+\mathrm{Nc}}$

where $\mathrm{Nt}=$ number of insects in a treated sample side, and $\mathrm{Nc}=$ number of insects in a control sample side. To give a meaningful explanation of $E P I$, we defined the $E P I_{0}$ as follows:

$\mathrm{EPI} 0=\frac{\mathrm{Nc} 1-\mathrm{Nc} 2}{\mathrm{Nc} 1+\mathrm{Nc} 2}$

where $\mathrm{Nc1}=$ number of insects in one control sample and $\mathrm{Nc} 2=$ number of insects in the other control sample. With $E P I$ significantly lower than $E P I_{0}=$ repel; $E P I$ showed no significance with $E P I_{0}=$ no preference; and $E P I$ significantly higher than $E P I_{0}=$ attract.

In bioassay 1 , the olfactory response of adult $P$. versicolora to odors of 2-g leaf samples was compared against clean air. For each sample, 40 insects were tested with five replicates for each test. In addition, to demonstrate preference of beetles between the willow species, a fourchoice olfactory bioassay (bioassay 2) was conducted with the two willows and two controls. The olfactometer was designed on the basis of the glass Y-tube olfactometer; the two long arms of the Y-tubes were connected with openings at the connection point. This is similar to bioassay 1 .

In bioassay 3, olfactometer bioassays were carried out with chemical analogs of the headspace VOCs. These were purchased from ChengShao Biological Technology Co., Ltd., Shanghai, China and Wuhan Yuanchen Technology Development Co., Ltd., Wuhan, China. The chemicals were dissolved separately in liquid paraffin and used in bioassay 2 . In each treatment, the volume of solution applied to filter paper was calculated based on the concentration of the corresponding compound in S. suchowensis or $S$. triandra. The filter paper with solution was placed in the blend-side of the container, whereas the filter paper with an equal volume of control solution (liquid paraffin) was placed in the control-side of the container. For each chemical analog, 40 insects were tested, with each test having five replicates.

\section{Statistical analyses}

Chi-square test was used to evaluate the difference in number of insects choosing between the blend arm and the control arm for data in both bioassays 1 and 3. One-way ANOVA was conducted to identify whether the numbers were significantly different among the two willow species treatments and the two controls in bioassay 2 . The difference in relative abundance of plant volatiles was also determined using the Chi-square test. One-way ANOVA was identified whether the EPI values were significantly different between the odor sources. All analyses were carried out using SPSS 19.0, SPSS Inc.

\section{Results}

\section{Olfactometer bioassays with leaves of $S$. suchowensis and $S$. triandra}

The response by P. versicolora to VOCs of willow leaves was tested in bioassays 1 and 2. For $S$. triandra vs. clean air, the selection rate indicated that the beetles significantly preferred clean air over the airborne substances (Table 1), with an $E P I$ value of $-0.45 \pm 0.18$ (Fig. 1a), while the $E P I_{0}$ of bioassay 1 was $-0.01 \pm 0.17$ (Fig. 1a), meaning that the beetles were significantly repelled by $S$. triandra VOCs (Table 1). For S. suchowensis vs. clean air, the selection rateshowed no significant difference (Table 1), and the EPI value was $-0.03 \pm 0.19$ (Fig. 1a), which was also insignificantly different compared with the $E P I_{0}$ (Fig. 1a). Therefore, somewhat unexpectedly, the olfactometer bioassay showed no preference for $S$. suchowensis by adult $P$. versicolora, so that plant odors of $S$. suchowensis might not attract the beetles, although it is a host plant in the field.
Table 1 Olfactory response of adult Plagiodera versicolora to willow leaves and clean air in bioassay 1 (Mean $\pm \mathrm{SD})$

\begin{tabular}{|c|c|c|c|c|c|}
\hline \multicolumn{2}{|l|}{ Group } & \multirow{2}{*}{$\begin{array}{l}\text { Pests that did not } \\
\text { make a selection }\end{array}$} & \multicolumn{2}{|c|}{ Pests that made a selection } & \multirow[t]{2}{*}{$P$ value } \\
\hline Treatment arm & Control arm & & Treatment & Control & \\
\hline Clean air & Clean air & $2.4 \pm 0.5(40)$ & $19.8 \pm 2.9$ & $17.8 \pm 2.7$ & 0.295 \\
\hline Salix triandra & Clean air & $2.0 \pm 1.6(40)$ & $10.4 \pm 2.3$ & $27.6 \pm 3.0$ & $* * *$ \\
\hline Salix suchowensis & Clean air & $3.6 \pm 0.9(40)$ & $17.6 \pm 3.2$ & $18.8 \pm 3.7$ & 0.599 \\
\hline
\end{tabular}

$* * * P<0.001$, indicates significant difference 
Fig. 1 a Host-selection behavior of Plagiodera versicolora to olfactory cues from leaves of the two willow species. Note: $\mathrm{X}$-axis shows the $E P I$ values. Different letters on the left of the horizontal bars indicate significant difference at $P<0.05$ between the corresponding leaf samples and clean air. b Selection behavior of Plagiodera versicolora to olfactory cues in different treatments. Note: $\mathrm{X}$-axis shows the EPI values. Different letters on the left of the horizontal bars indicate significant difference at $P<$ 0.05 between the corresponding treatment and the control. c Damage on leaves of Salix triandra and Salix suchowensis after foraging by adult Plagiodera versicolora for 24 hours. d The molecular structure of the detected volatile repellent and attractant (a)

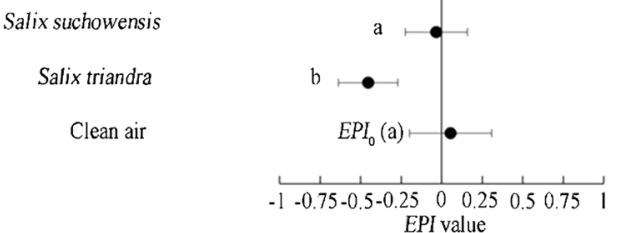

(b)

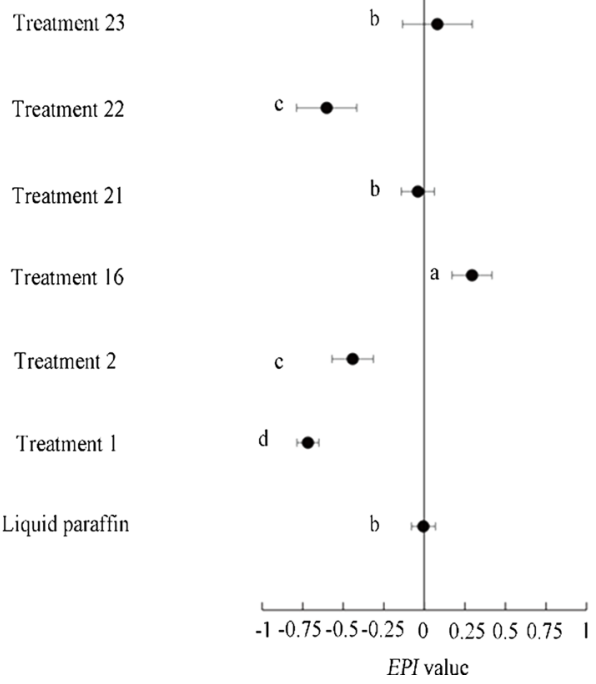

(c)

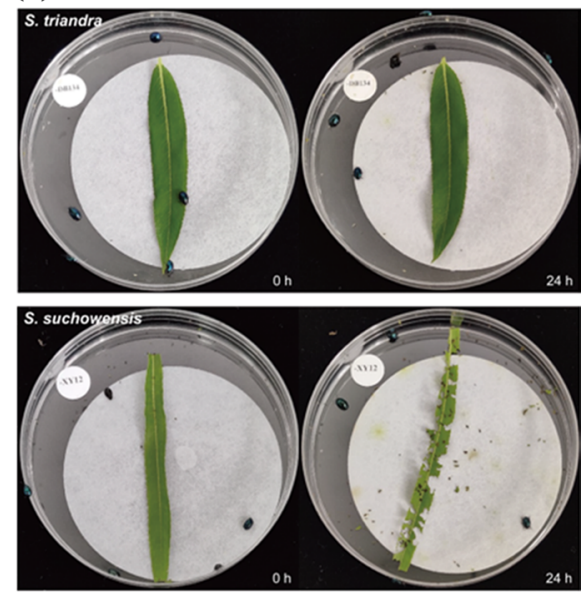

(d)<smiles>CC/C=C\CCOC(C)=O</smiles>

cis-3-hexen-1-ol acetate (1)<smiles>Cc1ccccc1C(C)C</smiles>

Subsequently, S. triandra, S. suchowensis and clean air were compared simultaneously, the selection rate indicated preference by the beetles as: $S$. triandra $<$ S. suchowensis $=$ clean air (Table 2).

\section{Identification of headspace VOCs from leaves of $S$. suchowensis and S. triandra}

To detect the VOCs triggering host discrimination for adult willow beetles, the headspace VOCs emitted from $S$. suchowensis and $S$. triandra leaves were analyzed by GC-MS. Twenty compounds were identified, 14 present in S. triandra and 11 in S. suchowensis (Table 3). For compounds detected from $S$. triandra, nine were species-specific
Table 2 Olfactory response of adult Plagiodera versicolora to willow leaves of two species and clean air simultaneously in bioassay 2. (Mean $\pm \mathrm{SD})$

\begin{tabular}{lllll}
\hline Pests that made a selection & & Pests that did not \\
Treatment arm 1 & Treatment arm 2 & Control arm 1 & Control arm 2 & a selection \\
\hline Salix suchowensis & Salix triandra & Clean air & Clean air & $2.6 \pm 1.5$ \\
$11.6 \pm 1.8^{\mathrm{a}}$ & $3.4 \pm 1.9^{\mathrm{b}}$ & $10.2 \pm 1.5^{\mathrm{a}}$ & $12.2 \pm 2.7^{\mathrm{a}}$ & \\
\hline
\end{tabular}

Different letters following the selection numbers of each arm indicate significant difference at $P<0.05$. 
Table 3 Headspace volatiles of Salix suchowensis and Salix triandra detected by SPMEGC-MS analysis

\begin{tabular}{|c|c|c|c|c|}
\hline \multirow[t]{2}{*}{ Compounds } & \multirow[t]{2}{*}{ Cas } & \multicolumn{3}{|c|}{ Relative abundance (\%) } \\
\hline & & Salix trandra & Salix suchowensis & Identification \\
\hline cis-3-hexenyl acetate & $3681-71-8$ & $44.68 \pm 3.28^{\mathrm{a}}$ & $7.52 \pm 1.58^{\mathrm{b}}$ & STD, RI, MS \\
\hline cis-3-hexenyl isovalerate & $35154-45-1$ & $31.88 \pm 2.32^{\mathrm{a}}$ & $52.18 \pm 4.02^{\mathrm{b}}$ & STD, RI, MS \\
\hline farnesane & $3891-98-3$ & $9.07 \pm 1.21^{\mathrm{a}}$ & $2.74 \pm 0.35^{\mathrm{b}}$ & STD, RI, MS \\
\hline cis-3-hexenyl 2-methylbutanoate & $53398-85-9$ & $3.26 \pm 0.57^{\mathrm{a}}$ & $7.16 \pm 0.32^{\mathrm{b}}$ & STD, RI, MS \\
\hline cis-3-hexenyl angelate & $84060-80-0$ & $2.96 \pm 0.36$ & $\mathrm{NF}$ & RI, MS \\
\hline 2-hexyl-1-decanol & $2425-77-6$ & $2.38 \pm 0.26$ & $\mathrm{NF}$ & STD, RI, MS \\
\hline$n$-tetradecane & $629-62-9$ & $2.37 \pm 0.35^{\mathrm{a}}$ & $1.36 \pm 0.47^{\mathrm{b}}$ & STD, RI, MS \\
\hline cis-7-hexadecenal & $56797-40-1$ & $2.24 \pm 0.38$ & NF & RI, MS \\
\hline trans-3-hexen-1-ol & $928-97-2$ & $2.18 \pm 0.45$ & NF & STD, RI, MS \\
\hline 2-butyl-1-octanol & $3913-2-8$ & $1.68 \pm 0.23$ & NF & STD, RI, MS \\
\hline $\begin{array}{l}\text { 1,5-dimethyl-1,2,3,4,4a,5,6,7,8,8a- } \\
\text { decahydronaphthalene }\end{array}$ & $66552-62-3$ & $1.14 \pm 0.32$ & NF & RI, MS \\
\hline cis-3-hexen-1-yl caproate & $31501-11-8$ & $1.06 \pm 0.35$ & NF & STD, RI, MS \\
\hline trans-4,8-dimethyl-1,3,7-nonatriene & 19945-61-0 & $0.65 \pm 0.30$ & NF & RI, MS \\
\hline$\alpha$-farnesene & $502-61-4$ & $0.55 \pm 0.27$ & $\mathrm{NF}$ & RI, MS \\
\hline$p$-cymene & $99-87-6$ & $\mathrm{NF}$ & $13.42 \pm 0.95$ & STD, RI, MS \\
\hline$o$-cymene & $527-84-4$ & NF & $10.60 \pm 0.82$ & STD, RI, MS \\
\hline phytol & $150-86-7$ & NF & $7.03 \pm 0.64$ & STD, RI, MS \\
\hline 2-methylbutan-2-ylbenzene & $2049-95-8$ & NF & $4.89 \pm 0.70$ & STD, RI, MS \\
\hline$n$-octadecyne & $629-89-0$ & NF & $2.78 \pm 0.41$ & STD, RI, MS \\
\hline$n$-dodecan & $112-40-3$ & NF & $1.59 \pm 0.35$ & STD, RI, MS \\
\hline Unknown chemical 1 & - & $2.36 \pm 0.39$ & $\mathrm{NF}$ & MS \\
\hline Unknown chemical 2 & - & $1.55 \pm 0.24^{\mathrm{a}}$ & $1.55 \pm 0.32^{\mathrm{a}}$ & MS \\
\hline Unknown chemical 3 & - & NF & $4.87 \pm 0.35$ & MS \\
\hline
\end{tabular}

Different letters following the concentrations of each compound indicate significant difference at $P<0.05$ between the two species, NF = not found.

$M S$ comparison of mass spectra with those of NIST2014, RI comparison of retention index with those reported in the literature (To obtain RI, saturated n-alkane standard solution (C7-C40 at a concentration of $1000 \mathrm{mg} / \mathrm{L}$ in hexane) was run under the same analytical conditions as the samples and thus the calculated RI were compared with those in the literature. https://webbook.nist.gov/), STD comparison of retention time and mass spectra of available standards
(Table 3) and were abundant as cis-3-hexenyl acetate, cis3-hexenyl isovalerate, farnesane and cis-3-hexenyl 2-methylbutanoate, while the remaining constituents were trace components. For the compounds detected in S. suchowensis, six were species-specific (Table 3).

\section{Effects of VOC analogs on finding hosts}

To analyze the effects of the emitted compounds on host finding or host identification, 15 commercially available standards were purchased. With these chemicals, 23 treatments were carried out in bioassay 3 and details are shown in Table 4.

Olfactory response to these analogs showed that adult $P$. versicolora were significantly repelled in treatment 1 and treatment 2 (Table 5), because both their numbers for choosing were significantly lower than the control. The EPI value was significantly lower $(P<0.001)$ than $E P I_{0}$ of bioassay 2
$(-0.01 \pm 0.07)($ Fig. 1b) and also showed beetle repellence in treatments 1 and 2. However, the EPI value of treatment 1 was $-0.72 \pm 0.12$ (Fig. 1b), which is significantly lower $(P=0.03)$ than treatment $2(-0.44 \pm 0.13)$ (Fig. 1b), indicating that the repelling effect decreases with a decrease in cis-3-hexenyl acetate. In contrast to treatments 1 and 2, the beetles exhibited significant preference to treatment 16 (Table 5). The EPI value of treatment 16 was $0.29 \pm 0.12$ (Fig. 1b), significantly higher $(P=0.02)$ than the $E P I_{0}$, demonstrating that $o$-cymene had significant effects on attracting adult $P$. versicolora.

In Table 3, VOCs profiling shows that S. suchowensis possessed both the repellent (cis-3-hexenyl acetate) and the species-specific attractant (o-cymene) but concentration of the repellent was much lower than in S. triandra. We mixed the two treatments for $S$. suchowensis in treatment 21 (Table 4) and the selection rates vs. control are shown in Table 5. There was no significant difference observed. The 
Table 4 Solutions of chemical analogs and treatments in olfactory response tests in bioassay 3

\begin{tabular}{|c|c|c|}
\hline Treatment & Chemical & $\begin{array}{l}\text { Concentra- } \\
\text { tion }(\mathrm{mg} / \mathrm{L})\end{array}$ \\
\hline 1 & cis-3-hexenyl acetate & 1.80 \\
\hline 2 & cis-3-hexenyl acetate & 0.30 \\
\hline 3 & cis-3-hexenyl isovalerate & 0.90 \\
\hline 4 & cis-3-hexenyl isovalerate & 1.50 \\
\hline 5 & farnesane & 0.40 \\
\hline 6 & farnesane & 0.10 \\
\hline 7 & cis-3-hexenyl 2-methylbutanoate & 0.10 \\
\hline 8 & cis-3-hexenyl 2-methylbutanoate & 0.20 \\
\hline 9 & $n$-tetradecane & 0.10 \\
\hline 10 & $n$-tetradecane & 0.05 \\
\hline 11 & 2-hexyl-1-decanol & 0.10 \\
\hline 12 & trans-3-hexen-1-ol & 0.10 \\
\hline 13 & 2-butyl-1-octanol & 0.10 \\
\hline 14 & cis-3-hexen-1-yl caproate & 0.05 \\
\hline 15 & $p$-cymene & 0.40 \\
\hline 16 & $o$-cymene & 0.30 \\
\hline 17 & phytol & 0.20 \\
\hline 18 & 2-methylbutan-2-ylbenzene & 0.10 \\
\hline 19 & $n$-octadecyne & 0.10 \\
\hline 20 & $n$-dodecan & 0.05 \\
\hline $21 *$ & $\begin{array}{l}\text { Dissolved } 1 \mathrm{ml} \text { treatment } 2 \text { and } 1 \mathrm{ml} \text { treat- } \\
\text { ment } 16\end{array}$ & \\
\hline $22 *$ & $\begin{array}{l}\text { Dissolved treatment } 1,3,5,7,9,11,12,13 \\
\text { and } 14 \text {, each of their volume is } 1 \mathrm{~mL} .\end{array}$ & \\
\hline $23^{*}$ & $\begin{array}{l}\text { Dissolved treatment } 2,4,6,8,10,15,16 \text {, } \\
17,18,19 \text { and } 20 \text {, each of their volume } \\
\text { is } 1 \mathrm{~mL} .\end{array}$ & \\
\hline
\end{tabular}

Treatment $21 *$ was used to test the masking effect of cis-3-hexenyl acetate over $o$-cymene. In which, cis-3-hexenyl acetate is in 1.80 $\mathrm{mg} / \mathrm{L}$ and $o$-cymene is in $0.30 \mathrm{mg} / \mathrm{L}$. Treatment $22 *$ was used to test the effect of resembling analogs for leaves of Salix triandra, in which, cis-3-hexenyl acetate is in $1.80 \mathrm{mg} / \mathrm{L}$, cis-3-hexenyl isovalerate is in $0.90 \mathrm{mg} / \mathrm{L}$, farnesane is in $0.40 \mathrm{mg} / \mathrm{L}$, cis-3-hexenyl 2-methylbutanoate is in $0.10 \mathrm{mg} / \mathrm{L}, n$-tetradecane is in $0.10 \mathrm{mg} / \mathrm{L}$, trans-3-hexen1 -ol is in $0.10 \mathrm{mg} / \mathrm{L}, 2$-butyl-1-octanol is in $0.10 \mathrm{mg} / \mathrm{L}$ and cis-3hexen-1-yl caproate is in $0.05 \mathrm{mg} / \mathrm{L}$. Treatment $23^{*}$ was used to test the effect of resembling analogs for leaves of Salix suchowensis, in which, cis-3-hexenyl acetate is in $0.30 \mathrm{mg} / \mathrm{L}$, cis-3-hexenyl isovalerate is in $1.50 \mathrm{mg} / \mathrm{L}$, farnesane is in $0.10 \mathrm{mg} / \mathrm{L}$, cis-3-hexenyl 2-methylbutanoate is in $0.20 \mathrm{mg} / \mathrm{L}, n$-tetradecane is in $0.05 \mathrm{mg} / \mathrm{L}, p$-cymene is in $0.40 \mathrm{mg} / \mathrm{L}, o$-cymene is in $0.30 \mathrm{mg} / \mathrm{L}$, phytol is in $0.20 \mathrm{mg} / \mathrm{L}$, 2-methylbutan-2-ylbenzene is in $0.10 \mathrm{mg} / \mathrm{L}, n$-octadecyne is in 0.10 $\mathrm{mg} / \mathrm{L}$ and $n$-dodecan is in $0.05 \mathrm{mg} / \mathrm{L}$

$E P I$ value of treatment $21(-0.04 \pm 0.15)$ is also not significantly different $(P=0.716)$ from the $E P I_{0}$ of bioassay 2 $(-0.01 \pm 0.07)$ (Fig. 1b), indicating the effect of the volatile attractant was masked by the repellent. Moreover, blends of VOCs resembling the compounds in the leaf samples of S. triandra and S. suchowensis were prepared as treatments 22 and 23 , respectively. The number of beetles attracted to treatment 22 was significantly different compared to those attracted to the solvent (Table 5). The $E P I_{0}$ was significantly higher than the EPI of treatment 22 (Fig. 1b; Table 5), indicating that the higher repulsive power of the blend was similar to the smells of $S$. triandra. However, treatment 23 failed in influencing the selection behavior of the beetles (Table 5; Fig. 1b), indicating that the beetles showed no preference to the blend, which was similar to the odors of S. suchowensis.

\section{Discussion}

Through years of empirical observation in the field, we found that $S$. suchowensis was a favorable host for the leaf beetle, $P$. versicolora, while $S$. triandra was a non-host plant. On a macro level, studies have shown that the preference of oligophagous herbivores, especially those feeding on plants of the same genus, were strongly affected by whether the plants were native species or not. Native species were more readily threatened by biotic stresses, while introduced species were more tolerant (Agrawal et al. 2005; Richard et al. 2019). In this study, $S$. suchowensis is a native species of Jiangsu province in southern China but $S$. triandra germplasm was collected in Heilongjiang province in northern China. Our study confirmed that adult $P$. versicolora was repelled by the chemicals from leaves of $S$. triandra, partially explaining why it is a non-host plant. For S. suchowensis, the olfactory bioassay indicated no preference by adult beetles for this favored host compared with clean air, although it produced volatile attractants. Subsequent analyses showed that the effect of the attractant was masked by the endogenous repellent. Therefore, locating host plants might not be triggered by olfactory signals. Enclosed starved beetles with leaves of $S$. triandra and $S$. suchowensis were only observed occasionally on the former, while leaves of the latter were consumed rapidly (Fig. 1c). Since $S$. triandra produced more concentrated cis-3-hexenyl acetate than $S$. suchowensis, this chemical might act as an antifeedant. However, $S$. triandra might also synthesize other nonvolatile antifeedants yet to be discovered.

Plant secondary metabolites, including C6-C10 hydrocarbons, aldehydes, alcohols, esters and their acetates, commonly serve as olfactory signals to insects (Matsui 2006). Besides directly attracting or repelling herbivore insects (Mitchell and McCashin 1994; Müller and Hilker 2000; Samantaray and Korada 2016; Castro et al. 2017; Mbitsemunda and Karangwa 2017), they also affected mating and reproduction behavior (Tabashnik 1985; Shelly 2000; Gerofotis et al. 2013; Molnár et al. 2017; Xu et al. 2017). As a typical VOC, cis-3-hexenyl acetate is widely known as an olfactory signal for herbivores (Sun et al. 2020), and also repelled male Anoplophora glabripennis Motschulsky (Nehme et al. 2009) and female Cephus cinctus Norton (Piesik et al. 2008) 
Table 5 Olfactory response of adult Plagiodera versicolora to chemical analogs in different treatments (Mean $\pm \mathrm{SD}$ )

\begin{tabular}{|c|c|c|c|c|c|}
\hline \multicolumn{2}{|l|}{ Group } & \multirow{2}{*}{$\begin{array}{l}\text { Pests did not } \\
\text { make a selection }\end{array}$} & \multicolumn{2}{|c|}{ Pests that made a selection } & \multirow[t]{2}{*}{$P$ value } \\
\hline Treatment & Control & & Treatment arm & Control arm & \\
\hline Liquid paraffin & Liquid paraffin & $2.2 \pm 1.1(40)$ & $18.8 \pm 1.5$ & $19.0 \pm 1.4$ & 0.833 \\
\hline 1 & Liquid paraffin & $3.2 \pm 1.8(40)$ & $5.2 \pm 1.8$ & $31.6 \pm 1.5$ & $<0.001$ \\
\hline 2 & Liquid paraffin & $1.2 \pm 0.4(40)$ & $10.8 \pm 2.5$ & $28.0 \pm 2.4$ & $<0.001$ \\
\hline 3 & Liquid paraffin & $1.6 \pm 0.9(40)$ & $19.4 \pm 2.6$ & $19.0 \pm 1.9$ & 0.788 \\
\hline 4 & Liquid paraffin & $1.0 \pm 0.7(40)$ & $19.2 \pm 2.2$ & $19.8 \pm 2.2$ & 0.673 \\
\hline 5 & Liquid paraffin & $2.8 \pm 1.8(40)$ & $18.2 \pm 2.9$ & $19.0 \pm 2.7$ & 0.669 \\
\hline 6 & Liquid paraffin & $1.8 \pm 1.3(40)$ & $19.2 \pm 1.5$ & $19.0 \pm 1.2$ & 0.822 \\
\hline 7 & Liquid paraffin & $3.0 \pm 1.9(40)$ & $19.0 \pm 3.7$ & $18.0 \pm 3.2$ & 0.657 \\
\hline 8 & Liquid paraffin & $2.4 \pm 1.1(40)$ & $19.4 \pm 1.1$ & $18.2 \pm 1.1$ & 0.128 \\
\hline 9 & Liquid paraffin & $3.2 \pm 1.3(40)$ & $17.6 \pm 2.5$ & $19.2 \pm 1.5$ & 0.656 \\
\hline 10 & Liquid paraffin & $2.2 \pm 1.3(40)$ & $19.0 \pm 1.6$ & $18.8 \pm 2.7$ & 0.262 \\
\hline 11 & Liquid paraffin & $3.0 \pm 1.4(40)$ & $18.8 \pm 2.2$ & $18.2 \pm 1.9$ & 0.89 \\
\hline 12 & Liquid paraffin & $2.4 \pm 1.1(40)$ & $18.6 \pm 2.7$ & $19.0 \pm 3.5$ & 0.844 \\
\hline 13 & Liquid paraffin & $2.8 \pm 1.3(40)$ & $18.4 \pm 2.6$ & $18.8 \pm 3.8$ & 0.851 \\
\hline 14 & Liquid paraffin & $2.6 \pm 1.1(40)$ & $18.2 \pm 0.8$ & $19.2 \pm 1.5$ & 0.235 \\
\hline 15 & Liquid paraffin & $2.6 \pm 2.2(40)$ & $17.8 \pm 2.8$ & $19.6 \pm 1.8$ & 0.265 \\
\hline 16 & Liquid paraffin & $2.0 \pm 1.4(40)$ & $24.6 \pm 2.7$ & $13.4 \pm 2.3$ & $<0.001$ \\
\hline 17 & Liquid paraffin & $2.6 \pm 1.5(40)$ & $18.8 \pm 2.4$ & $18.6 \pm 1.5$ & 0.919 \\
\hline 18 & Liquid paraffin & $3.8 \pm 2.8(40)$ & $18.0 \pm 2.4$ & $18.2 \pm 3.5$ & 0.879 \\
\hline 19 & Liquid paraffin & $2.6 \pm 2.1(40)$ & $19.0 \pm 1.4$ & $18.4 \pm 1.8$ & 0.577 \\
\hline 20 & Liquid paraffin & $1.2 \pm 1.1(40)$ & $20.2 \pm 0.8$ & $18.6 \pm 1.8$ & 0.127 \\
\hline 21 & Liquid paraffin & $1.2 \pm 1.3(40)$ & $18.6 \pm 1.9$ & $20.2 \pm 2.3$ & 0.267 \\
\hline 22 & Liquid paraffin & $2.6 \pm 1.1(40)$ & $7.4 \pm 3.4$ & $30.0 \pm 3.9$ & $<0.001$ \\
\hline 23 & Liquid paraffin & $2.8 \pm 1.9(40)$ & $20.2 \pm 4.6$ & $17.0 \pm 3.4$ & 0.253 \\
\hline
\end{tabular}

in finding hosts. Other effects of $c$ is-3-hexenyl acetate were also reported to be an inhibitor of pheromone response of spruce bark beetles (Ips typographius L.) (Zhang et al. 1999), while it enhanced activities of Cotesia glomerata L. and $C$. plutellae Kurdjumov, natural enemies of spruce bark beetles and thus reduced damage by the herbivores (Shiojiri et al. 2006). However, this chemical could also act as an attractant for some other insect pests in finding hosts (Schröder et al. 2015; Xin et al. 2017) and mates (Rouyar et al. 2015; Yu et al. 2015).

In this study, cis-3-hexenyl acetate was detected as a repellent (Fig. 1d) and the effect is directly proportionate to concentration: the higher level, the stronger repellency. Accumulated studies have revealed that concentration is a key factor determining the effect of VOCs. For instance, the essential oil of sweet wormwood (Artemisia annua L.) to two stored product insects: Tribolium castaneum Herbst and Callosobruchus maculatus L. worked at a $1 \%$ volume concentration but stronger repellency occurred when increased to $2 \%$ volume concentration (Tripathi et al. 2000). Rosemary oil effect on onion thrips (Thrips tabaci Linde.) was positively correlated with concentrations in the range of $0.1 \%$ to $10 \%$ (Koschier and Sedy 2003). Similar effects were observed for the silverleaf white fly,
Bemisia argentifolii Genn., where repellency increased with increased concentration (Zhang et al. 2004). The reduction in predation by a species of wolf-spider, Pardosa pseudoannulata Boesenberg, occurred with increasing plant essential oil concentration in the range of $100 \mathrm{ppm}$ to $1000 \mathrm{ppm}$ (Farid et al. 2019).

A constituent of plant oils, $O$-cymene, is recognized as a toxin to Sitophilus zeamais, Tribolium confusum (Tapondjou et al. 2005), and Bemisia tabaci (Bleeker et al. 2009). However, we found that $o$-cymene was an attractant (Fig. 1d) to adult $P$. versicolora. It is also noteworthy that $S$. suchowensis contains both repellent and attractant chemicals. Chemicals with opposite effects on insect behavior have been found in numerous plants such as in Olea europaea (Scarpati et al. 1993), Solanum tuberosum (Dickens 2000) and Pastinaca sativa (Carroll and Berenbaum 2002). Research has shown that functional chemicals should be mixed in the right ratio for insects to discern (Bruce and Pickett 2011). 


\section{Conclusions}

Since the favored host resulted in a neutral response in the olfactory experiment, finding a favorable host by the leaf beetles was not triggered by olfactory signals but likely through visual ones. In contrast, the repellency properties of the non-host willow was unambiguously mediated by olfactory signals. The functional chemicals detected in this study not only improve our understanding of interactions between herbivore insects and plants but also have potential to control willow beetles.

Open Access This article is licensed under a Creative Commons Attribution 4.0 International License, which permits use, sharing, adaptation, distribution and reproduction in any medium or format, as long as you give appropriate credit to the original author(s) and the source, provide a link to the Creative Commons licence, and indicate if changes were made. The images or other third party material in this article are included in the article's Creative Commons licence, unless indicated otherwise in a credit line to the material. If material is not included in the article's Creative Commons licence and your intended use is not permitted by statutory regulation or exceeds the permitted use, you will need to obtain permission directly from the copyright holder. To view a copy of this licence, visit http://creativecommons.org/licenses/by/4.0/.

\section{References}

Agrawal AA, Kotanen PM, Mitchell CE, Power AG, Godsoe W, Klironomos J (2005) Enemy release? An experiment with congeneric plant pairs and diverse above and belowground enemies. Ecology 86(11):2979-2989

Asare-Bediako E, Addo-Quaye AA, Mohammed A (2010) Control of diamondback moth (Plutella xylostella) on cabbage (Brassica oleracea var capitata) using intercropping with non-host crops. Am J Food Technol 5(4):269-274

Bleeker PM, Diergaarde PJ, Ament K, Guerra J, Weidner M, Schütz S, de Both MT, Haring MA, Schuurink RC (2009) The role of specific tomato volatiles in tomato-whitefly interaction. Plant Physiol 151(2):925-935

Bruce TJ, Pickett JA (2011) Perception of plant volatile blends by herbivorous insects-finding the right mix. Phytochemistry 72(13):1605-1611

Carroll MJ, Berenbaum MR (2002) Behavioral responses of the parsnip webworm to host plant volatiles. J Chem Ecol 28(11):2191-2201

Castro AM, Tapias J, Ortiz A, Benavides P, Góngora CE (2017) Identification of attractant and repellent plants to coffee berry borer. Hypothenemus hampei Entomol Exp Appl 164(2):120-130

Conchou L, Lucas P, Meslin C, Proffit M, Staudt M, Renou M (2019) Insect odorscapes: from plant volatiles to natural olfactory scenes. Front Physiol 10:972

Dickens JC (2000) Orientation of Colorado potato beetle to natural and synthetic blends of volatiles emitted by potato plants. Agr Forest Entomol 2(3):167-172

Farid IM, Chakira H, Cai W, Zhao J, Hua H (2019) Effect of some plant essential oils on the orientation and predation capacity of the predatory spider Pardosa pesudoannulata. J Asia-Pac Entomol 22(3):927-932

Gerofotis CD, Ioannou CS, Papadopoulos NT (2013) Aromatized to find mates: $\alpha$-pinene aroma boosts the mating success of adult olive fruit flies. PLoS One 8(11):e81336
Hori M, Ohuchi K, Matsuda K (2006) Role of host plant volatile in the host-finding behavior of the strawberry leaf beetle, Galerucella vittaticollis Baly (Coleoptera: Chrysomelidae). Appl Entomol Zool 41(2):357-363

Ishihara M, Ohgushi T (2008) Enemy-free space? Host preference and larval performance of a willow leaf beetle. Popul Ecol 50(1):35-43

Jactel H, Birgersson G, Andersson S, Schlyter F (2011) Non-host volatiles mediate associational resistance to the pine processionary moth. Oecologia 166(3):703-711

Jassbi AR (2003) Secondary metabolites as stimulants and antifeedants of Salix integra for the leaf beetle Plagiodera versicolora. Zeitschrift Fur Natur C 58:573-579

Kerr JL, Kelly D, Bader MKF, Brockerhoff EG (2017) Olfactory cues, visual cues, and semiochemical diversity interact during host location by invasive forest beetles. J Chem Ecol 43(1):17-25

King B, Crowe M, Blackmore MD (1998) Effects of leaf age on oviposition and on offspring fitness in the imported willow leaf beetle Plagiodera versicolora (Coleoptera: Chrysomelidae). J Insect Behav 11(1):23-36

Koschier EH, Sedy KA (2003) Labiate essential oils affecting host selection and acceptance of Thrips tabaci Lindeman. Crop Prot 22(7):929-934

Koschier EH, Nielsen M, Spangl B, Davidson MM, Teulon DAJ (2017) The effect of background plant odours on the behavioural responses of Frankliniella occidentalis to attractive or repellent compounds in a Y-tube olfactometer. Entomol Exp Appl 163(2):160-169

Matsui K (2006) Green leaf volatiles: hydroperoxide lyase pathway of oxylipin metabolism. Curr Opin Plant Biol 9(3):274-280

Mbitsemunda JPK, Karangwa A (2017) Analysis of factors influencing market participation of smallholder bean farmers in Nyanza district of southern province. Rwanda. J Agr Sci 9(11):99

McNair C, Gries G, Gries R (2000) Cherry bark tortrix, Enarmonia formosana: Olfactory recognition of and behavioral deterrence by nonhost angio- and gymnosperm volatiles. J Chem Ecol 26(4):809-821

Miller JR, Strickler KL (1984) Finding and accepting host plants. Chemical ecology of insects. Springer, New York, pp 127-157

Mitchell B, McCashin BG (1994) Tasting green leaf volatiles by larvae and adults of Colorado potato beetle, Leptinotarsa decemlineata. J Chem Ecol 20:753-769

Molnár BP, Tóth Z, Kárpáti Z (2017) Synthetic blend of larval frass volatiles repel oviposition in the invasive box tree moth. Cydalima perspectalis. J Pest Sci 90(3):873-885

Müller C, Hilker M (2000) The effect of a green leaf volatile on host plant finding by larvae of a herbivorous insect. Naturwissenschaften 87:216-219

Nehme M, Keena M, Zhang A, Baker T, Hoover K (2009) Attraction of Anoplophora glabripennis to male-produced pheromone and plant volatiles. Environ Entomol 38(6):1745-1755

Nishida R, Ohsugi T, Fukami H, Nakajima S (1990) Oviposition deterrent of a Rutaceae-feeding swallowtail butterfly, Papilio xuthus, from a non-host rutaceous plant. Orixa japonica. Agr Biol Chem 54(5):1265-1270

Nottingham SF, Hardie JIM (1993) Flight behaviour of the black bean aphid, Aphis fabae, and the cabbage aphid, Brevicoryne brassicae, in host and non-host plant odour. Physiol Entomol 18(4):389-394

Piesik D, Weaver DK, Runyon JB, Buteler M, Peck GE, Morrill WJ (2008) Behavioural responses of wheat stem sawflies to wheat volatiles. Agr Forest Entomol 10(3):245-253

Raupp MJ (1985) Effects of leaf toughness on mandibular wear of the leaf beetle. Plagiodera versicolora Ecol Entomol 10(1):73-79 
Raupp MJ, Denno RF (1983) Leaf age as a predictor of herbivore distribution and abundance. In: Deno RF, Mcclure MS (eds) Variable plants and herbivores in natural and managed systems. Elsevier, pp 103-104

Richard M, Tallamy DW, Mitchell AB (2019) Introduced plants reduce species interactions. Biol Invasions 21:983-992

Rouyar A, Deisig N, Dupuy F, Limousin D, Wycke MA, Renou M, Anton S (2015) Unexpected plant odor responses in a moth pheromone system. Front Physiol 6:148

Ruther J, Thiemann K (1997) Response of the pollen beetle Meligethes aeneus to volatiles emitted by intact plants and conspecifics. Entomol Exp Appl 84(2):183-188

Samantaray T, Korada R (2016) Electrophysiological and behavioural responses of sweetpotato weevil, Cylas formicarius to green leaf volatiles and terpenoids. Curr Sci 110(5):902-908

Scarpati ML, Scalzo RL, Vita G (1993) Olea europaea volatiles attractive and repellent to the olive fruit fly (Dacus oleae, Gmelin). J Chem Ecol 19(4):881-891

Schröder ML, Glinwood R, Webster B, Ignell R, Krüger K (2015) Olfactory responses of Rhopalosiphum padi to three maize, potato, and wheat cultivars and the selection of prospective crop border plants. Entomol Exp Appl 157(2):241-253

Shelly TE (2000) Flower-feeding affects mating performance in male oriental fruit flies Bactrocera dorsalis. Ecol Entomol 25(1):109-114

Shiojiri K, Ozawa R, Matsui K, Kishimoto K, Kugimiya S, Takabayashi J (2006) Role of the lipoxygenase/lyase pathway of host-food plants in the host searching behavior of two parasitoid species, Cotesia glomerata and Cotesia plutellae. J Chem Ecol 32(5):969-979

Silva SEB, Auad AM, Moraes JC, Alvarenga R, Fonseca MG, Marques FA, Nagata N (2019) Olfactory response of Mahanarva spectabilis (Hemiptera: Cercopidae) to volatile organic compounds from forage grasses. Sci Rep 9(1):10284

Sun YL, Dong JF, Huang LQ, Wang CZ (2020) The cotton bollworm endoparasitoid Campoletis chlorideae is attracted by cis-jasmone or cis-3-hexenyl acetate but not by their mixtures. Arthropod-Plant Interact 14(2):169-179

Tabashnik BE (1985) Deterrence of diamondback moth (Lepidoptera: Plutellidae) oviposition by plant compounds. Environ Entomol 14(5):575-578

Tapondjou A, Adler C, Fontem D, Bouda H, Reichmuth C (2005) Bioactivities of cymol and essential oils of Cupressus sempervirens and Eucalyptus saligna against Sitophilus zeamais Motschulsky and Tribolium confusum du Val. J Stored Prod Res 41(1):91-102

Tripathi A, Prajapati V, Aggarwal K, Khanuja S, Kumar S (2000) Repellency and toxicity of oil from Artemisia annua to certain stored-product beetles. J Econ Entomol 93(1):43-47

Uvah III, Coaker TH (1984) Effect of mixed cropping on some insect pests of carrots and onions. Entomol Exp Appl 36(2):159-167

Wade MJ, Breden F (1986) Life history of natural populations of the imported willow leaf beetle, Plagiodera versicolora (Coleoptera: Chrysomelidae). Ann Entomol Soc Am 79(1):73-79

Wang F, Deng J, Schal C, Lou Y, Zhou G, Ye B, Yin X, Xu Z, Shen L (2016) Non-host plant volatiles disrupt sex pheromone communication in a specialist herbivore. Sci Rep 6:32666

Xin ZJ, Li XW, Bian L, Sun XL (2017) Tea green leafhopper, Empoasca vitis, chooses suitable host plants by detecting the emission level of (3Z)-Hexenyl acetate. B Entomol Res 107(1):77-84

Xu H, Desurmont G, Degen T, Zhou G, Laplanche D, Henryk L, Turlings TC (2017) Combined use of herbivore-induced plant volatiles and sex pheromones for mate location in braconid parasitoids. Plant Cell Environ 40(3):330-339

Yoneya K, Kugimiya S, Takabayashi J (2009) Do adult leaf beetles (Plagiodera versicolora) discriminate between odors from intact and leaf-beetle-infested willow shoots? J Plant Interaction 4(2):125-129

Yu H, Feng J, Zhang Q, Xu H (2015) Z)-3-hexenyl acetate and 1 -undecanol increase male attraction to sex pheromone trap in Grapholita molesta (Busck) (Lepidoptera: Tortricidae. Int J Pest Manage 61(1):30-35

Zhang QH, Schlyter FJA (2004) Olfactory recognition and behavioural avoidance of angiosperm nonhost volatiles by conifer-inhabiting bark beetles. Agr Forest Entomol 6(1):1-20

Zhang QH, Schlyter F, Anderson P (1999) Green leaf volatiles interrupt pheromone response of spruce bark beetle. Ips typographus. J Chem Ecol 25(12):2847-2861

Zhang W, McAuslane HJ, Schuster DJ (2004) Repellency of ginger oil to Bemisia argentifolii (Homoptera: Aleyrodidae) on tomato. J Econ Entomol 97(4):1310-1318

Publisher's Note Springer Nature remains neutral with regard to jurisdictional claims in published maps and institutional affiliations. 